\title{
KAPPA OPIOID RECEPTORS MODULATE CARDIORESPIRATORY FUNCTION IN HINDBRAIN NUCLEI OF RAT ${ }^{1}$
}

\author{
A. H. HASSEN, ${ }^{2}$ G. FEUERSTEIN, and A. I. FADEN \\ Neurobiology Research Unit, Uniformed Services University of the Health Sciences, Bethesda, Maryland 20814
}

Received June 9, 1983; Revised February 27, 1984; Accepted February 28, 1984

\begin{abstract}
The respiratory and cardiovascular effects of selective kappa opioid agonists were compared following microinjection $(0.1 \mu \mathrm{l})$ into the nucleus ambiguus (NA) and the nucleus tractus solitarius (NTS) regions of spontaneously breathing and artificially respired pentobarbital-anesthetized rats. In spontaneously breathing animals, the benzomorphan derivative MRZ 2549 (MRZ, $3 \times 10^{-11}$ to $16 \times 10^{-9} \mathrm{~mol}$ ) elicited dose-related decreases of mean arterial pressure (MAP), heart rate (HR), and tidal volume (TV) following NA injection; bremazocine (BREM) decreased MAP, HR, and respiratory rate (RR). Following NTS injection, MRZ $(3 \times$ $10^{-10}$ to $\left.16 \times 10^{-9} \mathrm{~mol}\right)$ lowered MAP and TV, the highest dose also lowering HR and RR; BREM $\left(3 \times 10^{-9}\right.$ to $\left.16 \times 10^{-9} \mathrm{~mol}\right)$ decreased MAP and HR. Naloxone (200 $\mu \mathrm{g} / \mathrm{kg}$, i.v.) reversed the respiratory effects of MRZ without consistently altering cardiovascular activity. In ventilated animals, NA injections of MRZ or BREM $\left(3 \times 10^{-9}\right.$ to $\left.16 \times 10^{-9} \mathrm{~mol}\right)$ elicited a dose-related decrease of MAP without altering HR. These responses were not reversed by naloxone. The stereoisomer of BREM (+ BREM) was without effect at similar doses $\left(3 \times 10^{-9}\right.$ to $\left.16 \times 10^{-9} \mathrm{~mol}\right)$. MRZ $\left(16 \times 10^{-9} \mathrm{~mol}\right)$ elicited a naloxone-reversible tachycardia following NTS injection in ventilated animals; no other cardiovascular responses were observed following NTS administration of BREM $\left(16 \times 10^{-9} \mathrm{~mol}\right)$ or lower doses of MRZ. Dynorphin (1-13) $\left(6 \times 10^{-9}\right.$ to $\left.60 \times 10^{-9} \mathrm{~mol}\right)$ significantly lowered MAP without altering HR following NA microinjertions in ventilated animals; the lower dose decreased MAP following NTS injections. These observations suggest that in the NA, the benzomorphan derivatives elicit cardiovascular depressor responses mediated by kappa opioid receptors, whereas the naloxone-sensitive respiratory depression may be mediated in part by mu receptors in the NTS and NA. The selective responses to dynorphin (1-13) in the NTS and NA may indicate the presence of subgroups of kappa receptors in these nuclei.
\end{abstract}

Opioids elicit complex cardiovascular and respiratory responses following central administration (Florez et al., 1968; Laubie et al., 1977; Bolme et al., 1978). This may be due, in part, to multiple opioid receptors which mediate qualitatively different cardiorespiratory responses (Lord et al., 1977; Chang et al., 1979; Leslie et al., 1980). Using intraparenchymal injection of relatively selective mu and delta agonists in the rat, we have found that mu receptors in the region of nucleus tractus solitarius (NTS) as well as in the region of nucleus ambiguus (NA) may mediate increases in blood pressure and tachycardia

\footnotetext{
1 This work was supported by the Uniformed Services University of the Health Sciences Protocol R09211. The opinions or assertions contained herein are the private ones of the authors and are not to be construed as official or reflecting the view of the Department of Defense or the Uniformed Services University of the Health Sciences. The experiments reported herein were conducted according to the Guiding Principles in the Care and Use of Animals approved by the American Physiological Society. We wish to thank Eleanor M. Bell and Victoria Roane for the preparation of this manuscript and to acknowledge the expert technical assistance of Dan Snyder.

${ }^{2}$ To whom correspondence should be directed, at his present address: Department of Physiology, West Virginia School of Osteopathic Medicine, 400 North Lee Street, Lewisburg, WV 24901.
}

(Hassen et al., 1982, 1983). Anterior hypothalamic injections of $\mathrm{mu}$ receptor agonists in conscious rats also elicited pressor responses and tachycardia (Pfeiffer et al., 1983a, b). Moreover, the endogenous opioids methionine- and leucine-enkephalin elicit cardiovascular responses from the NTS that are quite similar to those produced by highly selective mu agonists (Petty and De Jong, 1983). In contrast, $\beta$-endorphin, a selective ligand for the putative epsilon receptor (Schulz et al., 1981a), decreases blood pressure and heart rate following NTS microinjection in the rat (Petty and De Jong, 1982). Thus, other opioid receptor types may also function in cardiovascular regulation.

NTS and NA also contain dynorphin-immunoreactive peptides (Khachaturian et al., 1982; Molineaux et al., 1982; Feuerstein et al., 1983). These dynorphin-related peptides exhibit relative selectivity toward the kappa opioid receptor and have been proposed as endogenous ligands for this receptor (Chavkin et al., 1982; Oka et al., 1982; Schulz et al., 1982). Kappa receptors have also been localized in the hindbrain (Della Bella et al., 1978; Pfeiffer and Herz, 1982). Although dynorphin and other kappa agonists elicit cardiorespiratory responses following hypothalamic microinjection (Feuerstein and Faden, 1982; Pfeiffer et al., 1983a, b), no cardiovascular or respiratory function has been ascribed to the kappa system in the hindbrain. In the present study we examined the cardiovascular responses 
to MRZ 2549 and bremazocine, benzomorphan derivatives which are selective for kappa receptors (Romer et al., 1980; Schulz and Wuster, 1981) following microinjection into NTS and NA. To distinguish the respiratory and cardiovascular actions of these compounds, which may be interactive (Bellet et al., 1980; Hassen et al., 1983), experiments were performed using spontaneously breathing and artificially ventilated animals. The cardiovascular responses to the endogenous dynorphin peptides, dynorphin (1-13) (Dyn 13) and dynorphin (1-8) (Dyn 8), were examined using artificially ventilated animals.

\section{Materials and Methods}

Surgical preparation. Male Sprague-Dawley rats (250 to $300 \mathrm{gm}$ ) were anesthetized with pentobarbital $(60 \mathrm{mg} / \mathrm{kg}$, i.p., plus supplemental doses as needed). The femoral artery and vein were cannulated, a tracheal cannula was inserted, and the animal was placed in a Kop stereotaxic device. The obex was exposed by removing the middle portion of the occipital bone. A pulled glass capillary (outer diameter $14 \mu \mathrm{m}$ ), prefilled with $0.9 \%$ saline (vehicle) or opioid solution, was inserted into the brainstem according to the following coordinates measured from the obex: NA, lateral $=1.9 \mathrm{~mm}$, anteroposterior $=+1.9$ $\mathrm{mm}$, ventral $=-2.3 \mathrm{~mm}$ from the dorsal surface of the hindbrain; NTS, lateral $=0.5 \mathrm{~mm}$, anteroposterior $=$ obex, ventral $=-0.5 \mathrm{~mm}$ from the dorsal surface of the hindbrain. Systolic and diastolic blood pressures were obtained through a Narco RP 1500 i pressure transducer. Mean arterial pressure (MAP) was calculated as $1 / 3$ (pulse pressure) + diastolic pressure. Heart rate (HR) was derived from the arterial recording by means of a Narco Biotachograph. Respiration rate (RR) and relative tidal volume (TV) were recorded with a Narco Impedance Pneumograph. Arterial blood gas was measured using a Corning $\mathrm{pH} /$ Blood Gas 164/2. Rectal temperature was monitored with a thermoprobe (YSI) and was controlled with a heating pad. Artificially respired animals were ventilated with a Harvard Apparatus Rodent Respirator.

Experimental procedure. Each animal was continuously monitored for $15 \mathrm{~min}$ following a single microinjection of $0.1 \mu \mathrm{l}$ of vehicle $(0.9 \%$ $\mathrm{NaCl}$ ), MRZ 2549 (5,9-dimethyl, 2',1-hydroxy-2-(2-methoxypropyl)6,7-benzomorphan, MRZ; kindly provided by Doctor H. Merz, Boehringer, Ingleheim), (-)-bremazocine or $(+)$-bremazocine (BREM, kindly provided by Doctor R. Maurer, Sandoz, Basel, Switzerland). The endogenous opioids dynorphin (1-13) (Dyn 13, Peninsula Labo- ratory) or dynorphin (1-8) (Dyn-8, Peninsula Laboratory) were also microinjected into the two hindbrain regions. Microinjections were administered using a Medical Systems Corporation PPM2 Pneumatic Pump. At the conclusion of the observation period, naloxone (generously provided by Endo Laboratory) was injected intravenously (200 $\mu \mathrm{g} / \mathrm{kg}$ ), and the responses were followed for another $15 \mathrm{~min}$. In some experiments animals were monitored for up to $60 \mathrm{~min}$ following microinjection of the opioids to exclude any secondary or late onset responses to the opioids. At the conclusion of the experiment, the capillary was raised, filled with saturated fast green solution, and returned to the same stereotaxic coordinates as the injections. The fast green solution was injected to mark the site; the brainstem was removed, frozen on dry ice, mounted on a cryostat, sliced $(100 \mu \mathrm{m})$ and mounted on a glass slide. Placement of the cannulae was confirmed microscopically (Paxinos and Watson, 1982).

Statistical analysis. The cardiovascular and respiratory responses to the opioids or saline were compared by means of an unpaired Student's $t$ test (two-tailed), analysis of variance (ANOVA), and Duncan's Multiple Range Test. Blood gas values were compared using ANOVA and unpaired Student's $t$ test. Statistical significance was accepted for $p<$ 0.05 . Data in the text or in the figures are the maximum responses (mean $\pm \mathrm{SE}$ ) for the indicated number of rats.

\section{Results}

The saturated fast green solution, injected in a larger volume $(0.3 \mu \mathrm{l})$ than was used for opioid or saline injections $(0.1 \mu \mathrm{l})$ in order to leave a recognizable mark, diffused approximately 500 $\mu \mathrm{m}$ from the injection site. NTS injections spread to the commissural nucleus of the tractus solitarius and the dorsal motor nucleus of the vagus (Fig. 1), whereas NA injections diffused to the NA and the adjacent Al catecholamine group (Fig. 2). There was no evidence of diffusion of fast green from one injection site to the other within the experimental period. Moreover, different patterns of cardiorespiratory responses were elicited from the two regions of the hindbrain, a further indication that the two injection sites did not overlap. Microinjections into other hindbrain regions elicited either no cardiorespiratory responses (pyramidal tract caudal to the obex) or responses which were smaller and had longer latencies than

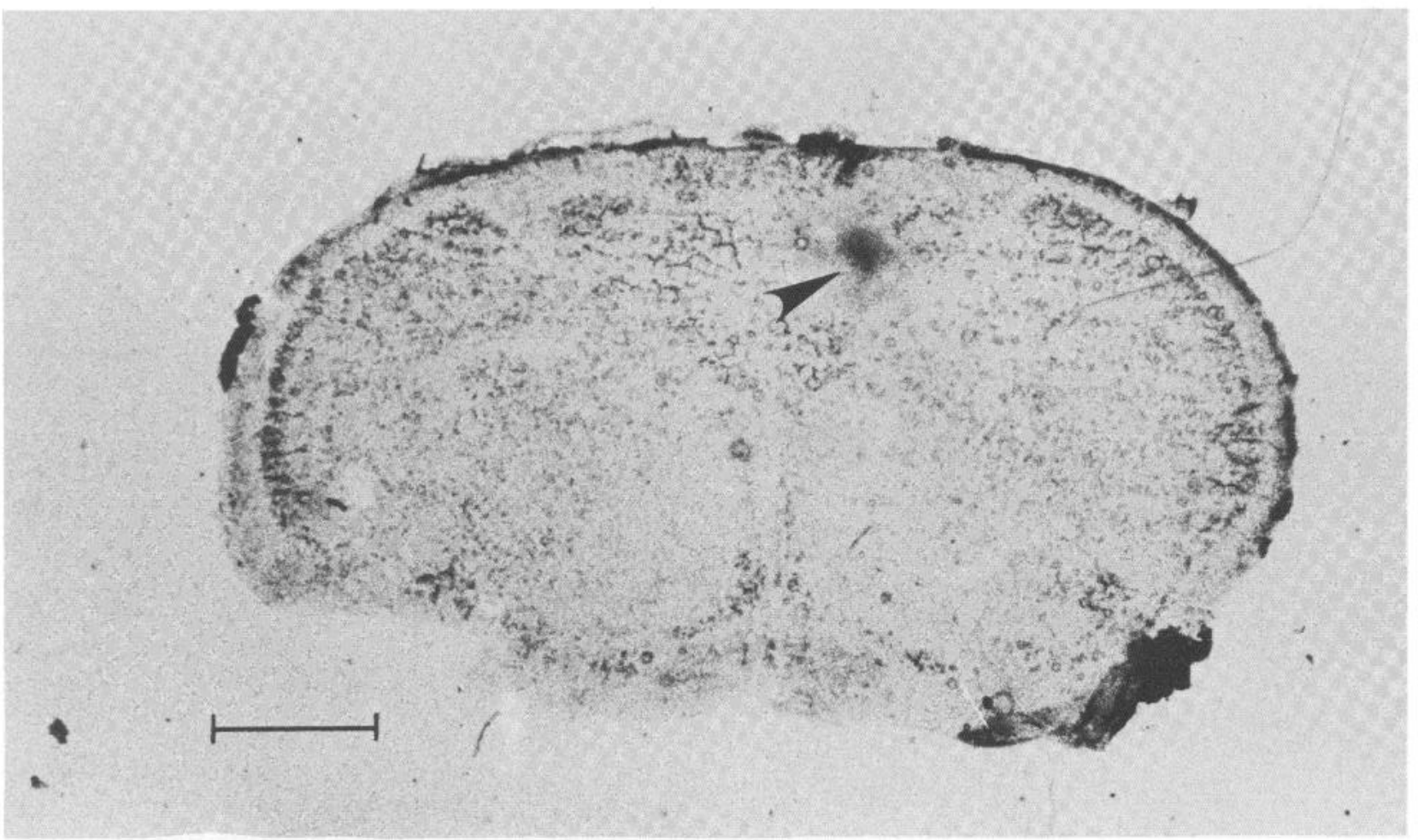

Figure 1. Photograph of dorsomedial injection site (fast green indicated with arrow). Calibration bar is $1 \mathrm{~mm}$. 


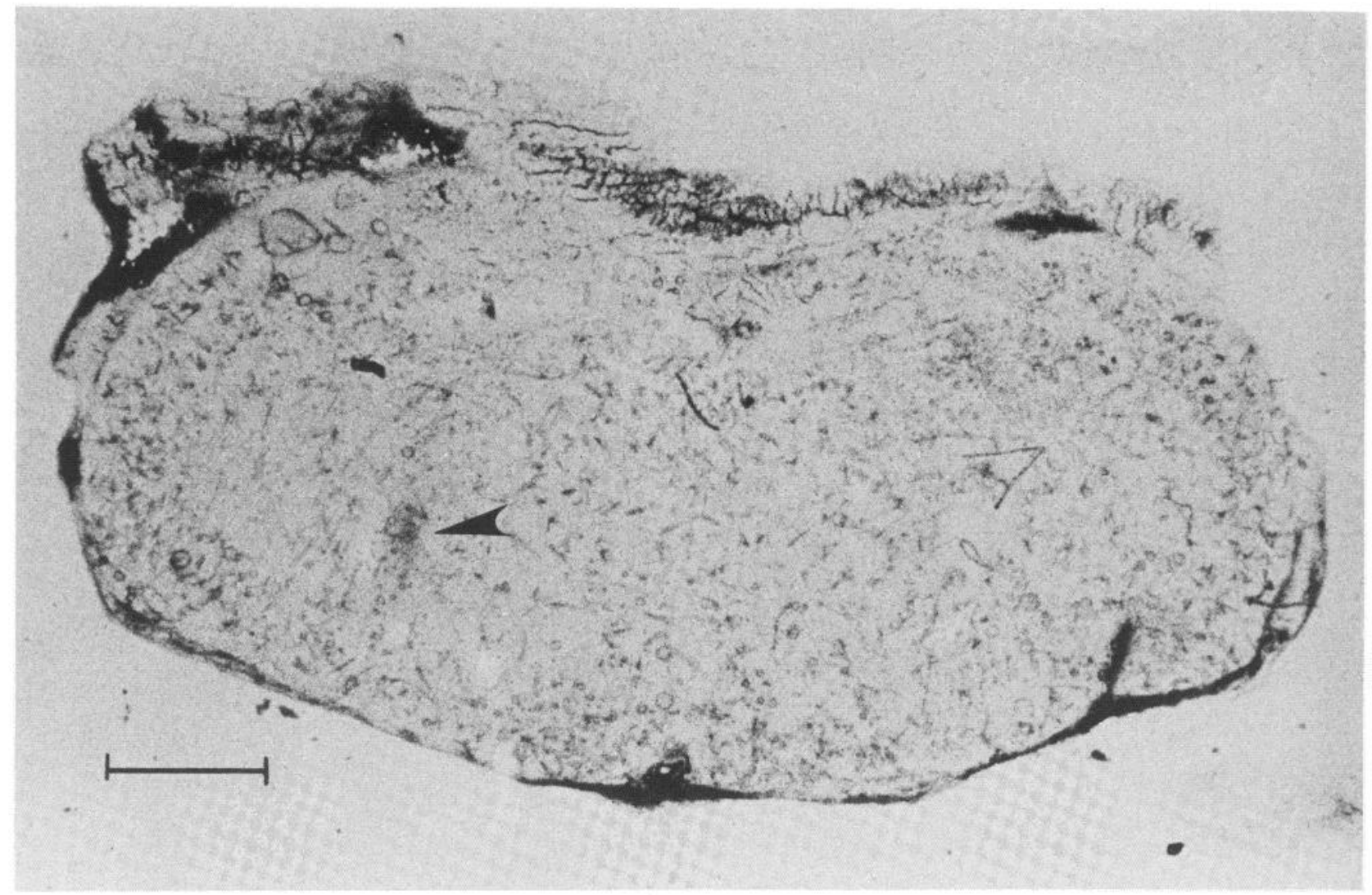

Figure 2. Photograph of ventrolateral injection site (fast green indicated with arrow). Calibration bar is $1 \mathrm{~mm}$.

those which were elicited from the NTS or NA (e.g., spinal vestibular nucleus; data not shown).

Effect of MRZ and BREM injected into the NA: Spontaneous respiration. Mean control values were: MAP, $105+2 \mathrm{~mm} \mathrm{Hg}$; $\mathrm{HR}, 349 \pm 6$ beats/min; RR, $74 \pm 2$ breaths/min. There were no differences between treatment groups.

Saline injections had no significant effect on MAP $(-2 \pm 2$ $\mathrm{mm} \mathrm{Hg})$, HR $(-1+3$ beats/min), or respiration. MRZ elicited dose-related decreases in MAP, HR, and TV (Fig. 3). Although low doses $\left(3 \times 10^{-11}\right.$ and $\left.3 \times 10^{-10} \mathrm{~mol}\right)$ produced small decreases in MAP and HR, higher doses $\left(3 \times 10^{-9}\right.$ and $\left.16 \times 10^{-9} \mathrm{~mol}\right)$ elicited significant hypotension $(-27+8$ and $-24 \pm 4 \mathrm{~mm} \mathrm{Hg})$ and bradycardia ( $-36 \pm 7$ and $-36 \pm 5$ beats $/ \mathrm{min})$. In contrast, TV was progressively decreased over the entire range of doses (Fig. 3); the decrease ranged from $-8 \pm 3 \%$ to $-24 \pm 6 \%$ and was not accompanied by significant changes in RR (Fig. 3).

BREM elicited similar but smaller decreases in MAP $(-3 \pm$ 2 to $-12 \pm 3 \mathrm{~mm} \mathrm{Hg}$ ) and $\mathrm{HR}(0$ to $-15 \pm 3$ beats $/ \mathrm{min})$, accompanied by small decreases in RR (Fig. $3, A$ to $D$ ). The $\mathrm{ED}_{50}$ for the decrease in MAP was $5 \times 10^{-10} \mathrm{~mol}$ and $7 \times 10^{-10}$ mol for MRZ and BREM, respectively, $\mathrm{ED}_{50}$ for $\mathrm{HR}$ changes were $3.5 \times 10^{-10} \mathrm{~mol}$ and $6 \times 10^{-10} \mathrm{~mol}$, respectively, for MRZ

Figure 3. Cardiovascular and respiratory responses following NA microinjections in spontaneously breathing animals. Measurements were made $15 \mathrm{~min}$ after NA microinjection. Solid circles and solid lines refer to MRZ; solid triangles and dashed lines refer to BREM. Hatched areas delineate the mean $\pm \mathrm{SE}$ of saline-treated animals. The number of animals in each group was as follows: saline, 5; MRZ, $3 \times 10^{-11} \mathrm{~mol}$, 6 ; $3 \times 10^{-10} \mathrm{~mol}, 6 ; 3 \times 10^{-9} \mathrm{~mol}, 6 ; 16 \times 10^{-9} \mathrm{~mol}, 6$; BREM, $3 \times 10^{-10}$ mol, $6 ; 3 \times 10^{-9} \mathrm{~mol}, 4 ; 16 \times 10^{-9} \mathrm{~mol}, 6$. **, Different from saline, $p<$ 0.01 (Duncan's Multiple Range Test). *, Different from saline, $p<0.05$ (Duncan's Multiple Range Test). $\ddagger$, Different from saline, $p<0.05$ (unpaired, two-tailed Student's $t$ test).
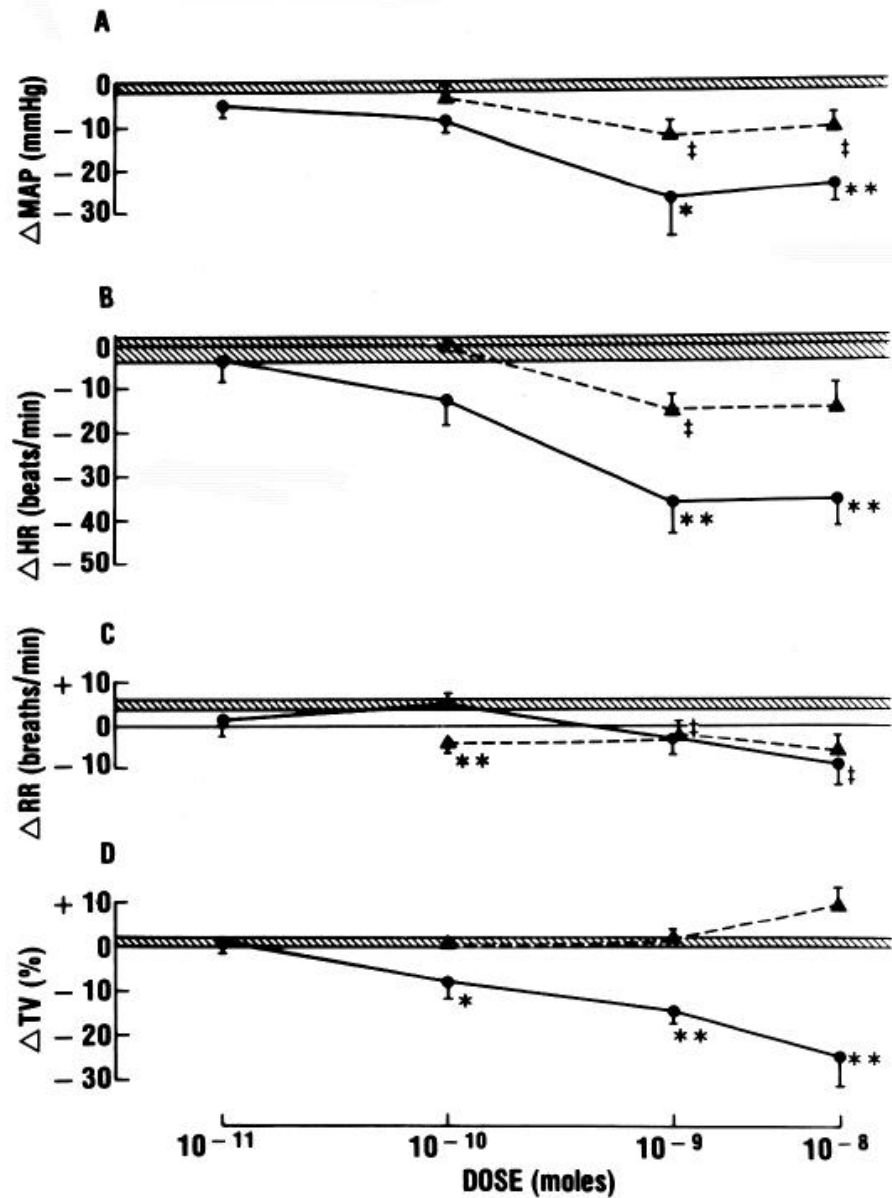
and BREM. Thus, in spite of the different respiratory effects of these compounds, the cardiovascular responses were similar.

Cardiovascular and respiratory responses occurred within minutes of the injection and reached a maximum within 15 min. A gradual return to control was observed, and the total response had a duration of less than $30 \mathrm{~min}$. Naloxone administration $(200 \mu \mathrm{g} / \mathrm{kg}$, i.v.) increased RR of MRZ-treated animals but did not consistently change TV (Fig. 4, $C$ and $D$ ). Moreover, neither MAP nor HR was consistently altered by the opioid antagonist (Fig. 4, $A$ and $B$ ).

Artificial respiration. Base line MAP and HR for this group were $108 \pm 2 \mathrm{~mm} \mathrm{Hg}$ and $360 \pm 6 \mathrm{beats} / \mathrm{min}$, respectively. The respirator was set at 72 breaths $/ \mathrm{min}$; TV was $1.6 \mathrm{ml}$. Spontaneously respired animals had lower $(p<0.01) \mathrm{pH}(7.308 \pm$ $0.008)$ and $\mathrm{pO}_{2}(60.3 \pm 1.1 \mathrm{~mm} \mathrm{Hg})$ than artificially respired animals $\left(\mathrm{pH} 7.376 \pm 0.006 ; \mathrm{pO}_{2} 66.5 \pm 1.7 \mathrm{~mm} \mathrm{Hg}\right)$; however, no significant differences in MAP and HR were observed.

Saline injections produced slight increases in MAP and HR. However, both MRZ and BREM elicited dose-related decreases in MAP (Fig. 5); MRZ $\left(10 \times 10^{-9} \mathrm{~mol}\right.$ and $\left.16 \times 10^{-9} \mathrm{~mol}\right)$ decreased MAP $16 \pm 3$ and $24 \pm 3 \mathrm{~mm} \mathrm{Hg}$, respectively, and BREM $\left(3 \times 10^{-9} \mathrm{~mol}\right)$ lowered MAP $9 \pm 2 \mathrm{~mm} \mathrm{Hg}$. The higher dose of BREM $\left(16 \times 10^{-9} \mathrm{~mol}\right)$ decreased both HR $(-11 \pm 5$ beats/min) and MAP $(-20 \pm 2 \mathrm{~mm} \mathrm{Hg})$. The time course and
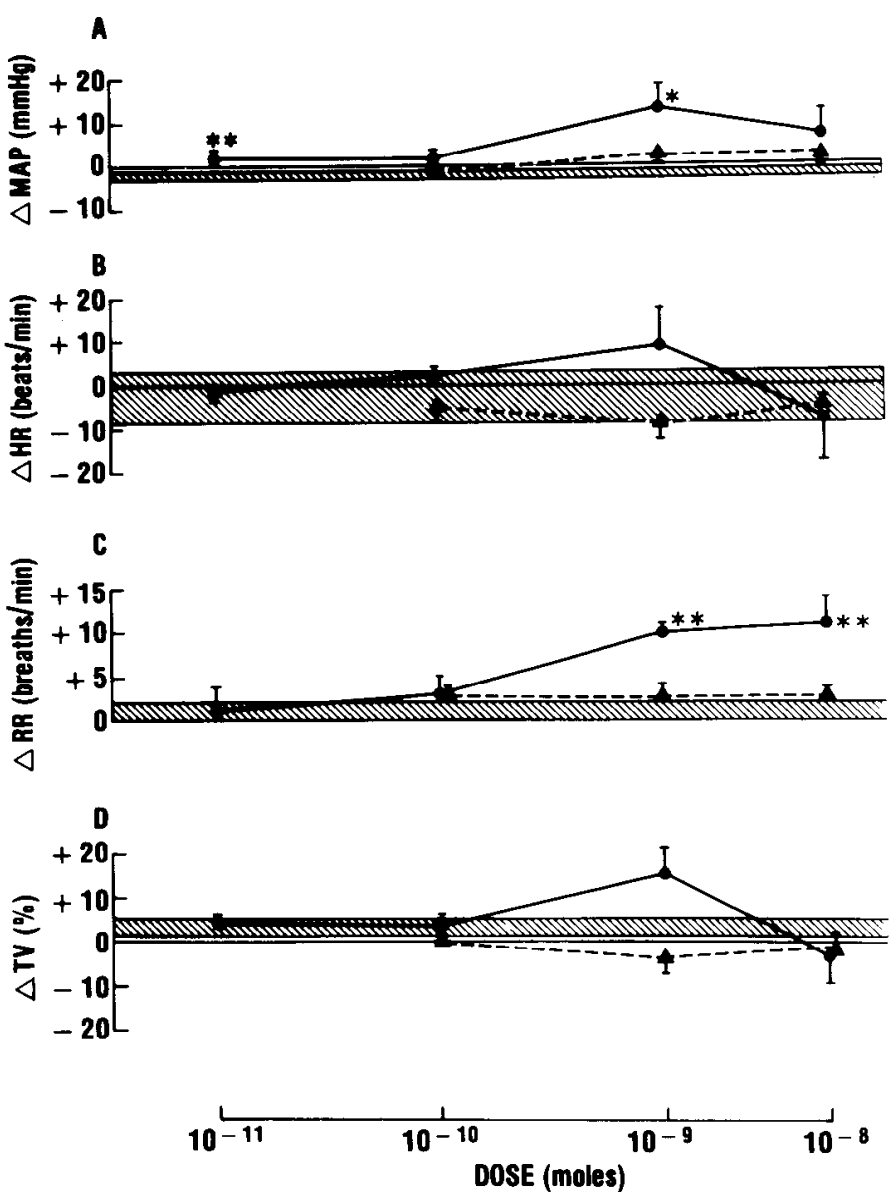

Figure 4. Cardiovascular and respiratory responses to intravenous naloxone $(200 \mu \mathrm{g} / \mathrm{kg})$ following NA microinjections to spontaneously breathing animals. Measurements were made 5 min after intravenous injection. Solid circles and solid lines refer to MRZ; solid triangles and dashed lines refer to BREM. Hatched areas delineate the mean $\pm \mathrm{SE}$ of saline-treated animals. The number of animals in each group was as follows: saline, 5 ; MRZ, $3 \times 10^{-11} \mathrm{~mol}, 6 ; 3 \times 10^{-10} \mathrm{~mol}, 6 ; 3 \times 10^{-9} \mathrm{~mol}$, $6 ; 16 \times 10^{-9} \mathrm{~mol}, 4 ; \mathrm{BREM}, 3 \times 10^{-10} \mathrm{~mol}, 6 ; 3 \times 10^{-9} \mathrm{~mol}, 4 ; 16 \times 10^{-9}$ mol, 6. **, Different from saline, $p<0.01$ (unpaired; two-tailed Student's $t$ test). *, Different from saline, $p<0.05$ (unpaired, two-tailed Student's $t$ test.
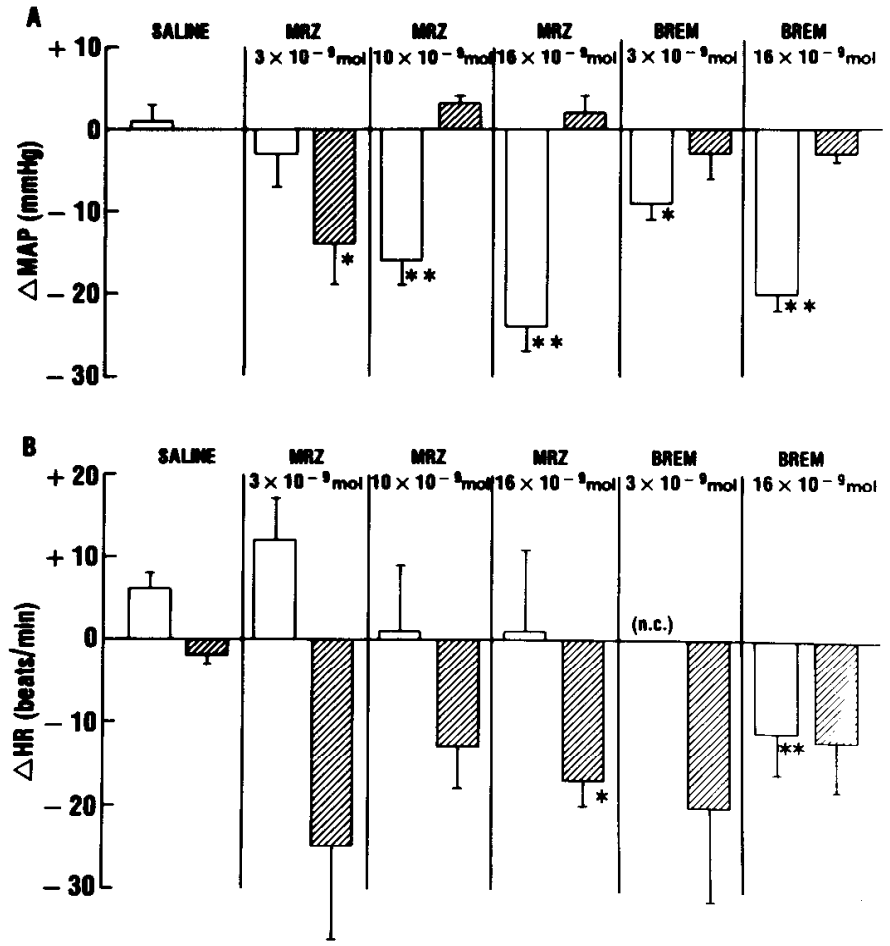

Figure 5. Cardiovascular responses following NA microinjections and intravenous naloxone $(200 \mu \mathrm{g} / \mathrm{kg})$ to artificially ventilated animals. Measurements were made $15 \mathrm{~min}$ after NA microinjections and $5 \mathrm{~min}$ after intravenous injection. Open bars are responses following NA injection (mean $\pm \mathrm{SF}, 15$ min after microinjestion); hatched hars are responses following naloxone (mean $\pm \mathrm{SE}, 5 \mathrm{~min}$ after intravenous injection). The number of animals in each group was as follows: saline, 5; MRZ, $3 \times 10^{-9} \mathrm{~mol}, 6$; $10 \times 10^{-9} \mathrm{~mol}, 9 ; 16 \times 10^{-9} \mathrm{~mol}, 6$; BREM, 3 $\times 10^{-9} \mathrm{~mol}, 5 ; 16 \times 10^{-9} \mathrm{~mol}, 4 . * *$, Different from saline, $p<0.01$ (unpaired, two-tailed Student's $t$ test. *, Different from saline, $p<0.05$ (unpaired, two-tailed Student's $t$ test).

duration of these responses were the same as those of spontaneously breathing animals. Naloxone $(200 \mu \mathrm{g} / \mathrm{kg}$, i.v. $)$ again failed to reverse these responses; however, a slowing of HR was observed. To ascertain whether the absence of reversal by naloxone was dose related, two animals were administered a dose $(1 \mathrm{mg} / \mathrm{kg}$, i.v.) 10 times greater than that required to terminate the actions of mu agonists $(100 \mu \mathrm{g} / \mathrm{kg})$; this dose was also without effect (Fig. 6). The inactive stereoisomer (+)bremazocine $\left(3 \times 10^{-9}\right.$ to $\left.16 \times 10^{-9} \mathrm{~mol}\right)$ did not change either $\operatorname{MAP}(-3 \pm 2 \mathrm{~mm} \mathrm{Hg})$ or HR $(-2 \pm 6$ beats $/ \mathrm{min})$.

Effect of $M R Z$ and BREM injected into the NTS: Spontaneous respiration. Pre-injection values for MAP, HR, and RR were $101 \pm 2 \mathrm{~mm} \mathrm{Hg}, 338 \pm 6$ beats $/ \mathrm{min}$, and $70 \pm 1$ breaths $/ \mathrm{min}$, respectively. There were no differences between the different groups.

Saline injections had no significant effect on $\mathrm{HR}$ and $\mathrm{RR}$ or respiration. High doses of MRZ $\left(3 \times 10^{-10}\right.$ to $\left.16 \times 10^{-9} \mathrm{~mol}\right)$ decreased MAP and TV (Fig. 7). HR and RR were decreased following the highest dose of MRZ $\left(16 \times 10^{-9} \mathrm{~mol}\right)$. BREM elicited a reduction of TV that was not significantly greater than saline; however, doses of $3 \times 10^{-9}$ and $16 \times 10^{-9} \mathrm{~mol}$ elicited decreased MAP and HR (Fig. 7).

As was seen with NA injections, the responses occurred within minutes, reached a maximum within $15 \mathrm{~min}$, and had a total duration of less than $30 \mathrm{~min}$. Naloxone $(200 \mu \mathrm{g} / \mathrm{kg}$, i.v.) reversed the depression of $\mathrm{TV}$ induced by $\mathrm{MRZ}$ and elevated the MAP of both MRZ- and BREM-treated animals; HR responses were not significant (Fig. 8).

Artificial respiration. Base line MAP and $\mathrm{HR}$ were $108 \pm 2$ $\mathrm{mm} \mathrm{Hg}$ and $345 \pm 8$ beats $/ \mathrm{min}$; RR was set at 72 breaths $/ \mathrm{min}$, 


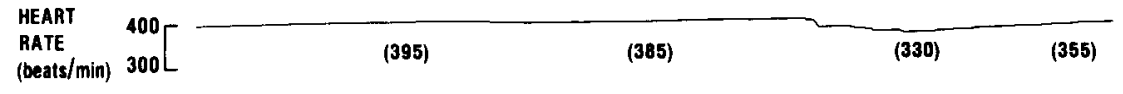

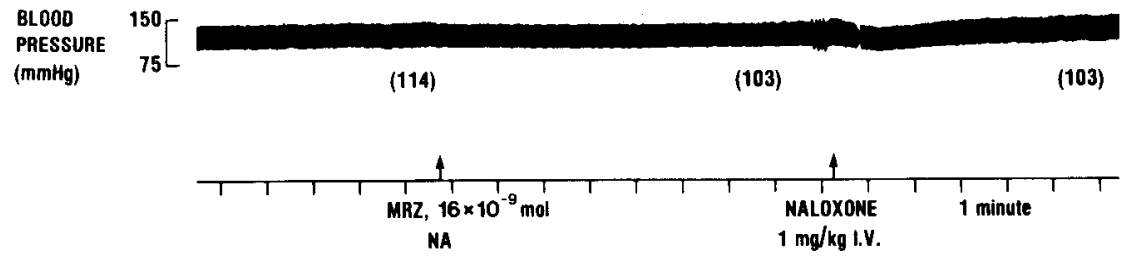

Figure 6. Physiograph record of responses following NA injection of MRZ (16 $\times 10^{-9}$ mol) and naloxone (1 mg/kg, i.v.) to artifically respired animal. Heart rate and mean arterial pressure are shown in parenthesis.
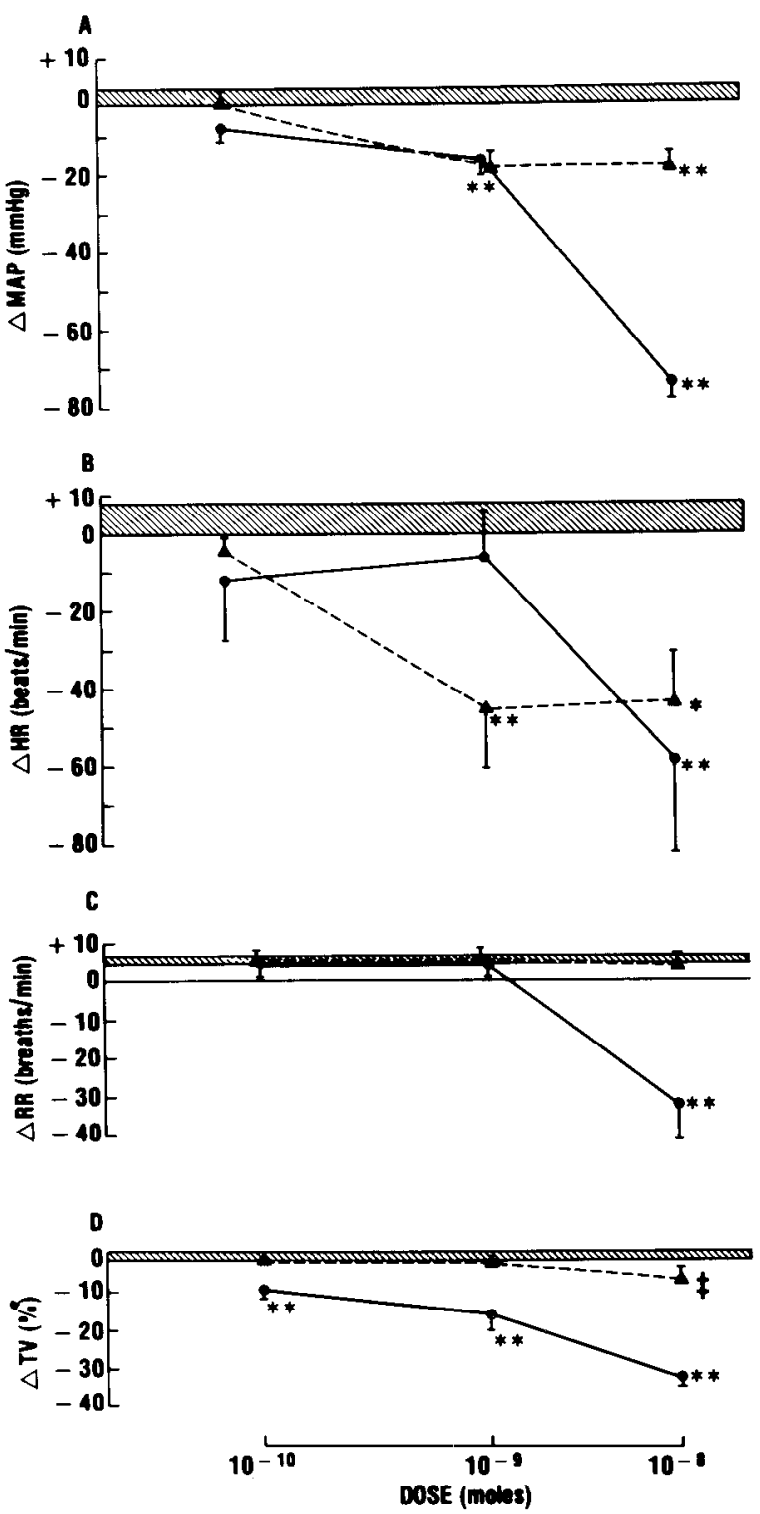

Figure 7. Cardiovascular and respiratory responses following NTS microinjection in spontaneously breathing animals. Measurements were made $15 \mathrm{~min}$ after NTS microinjections. Solid circles and solid lines refer to MRZ; solid triangles and dashed lines refer to BREM. Hatched arcas delineate the mean $\pm \mathrm{SE}$ of saline-trcated animals. The number of animals in each group was as follows: saline, 10 ; MRZ, $3 \times$ $10^{-10} \mathrm{~mol}, 6 ; 3 \times 10^{-9} \mathrm{~mol}, 9 ; 16 \times 10^{-9} \mathrm{~mol}, 6$; BREM, $3 \times 10^{-10} \mathrm{~mol}$, and TV was $1.6 \mathrm{ml}$. There were no differences between the groups. Spontaneously breathing animals had a significantly ( $p$ $<0.01)$ lower $\mathrm{pH}(7.298 \pm 0.015)$ and $\mathrm{pO}_{2}(61.0 \pm 1.5 \mathrm{~mm} \mathrm{Hg})$ than artificially respired animals $\left(\mathrm{pH} 7.363 \pm 0.002 ; \mathrm{pO}_{2} 71.1\right.$ $\pm 1.8 \mathrm{~mm} \mathrm{Hg}$ ); however, no differences in initial MAP or HR were observed between artificially and spontaneously respired animals.

Saline injections produced no significant change in MAP (-3 $\pm 4 \mathrm{~mm} \mathrm{Hg})$ and $\mathrm{HR}(+2 \pm 6$ beats/min). Doses of MRZ or BREM which elicited significant responses in spontaneously breathing animals were without effect when ventilation was controlled (Fig. 9). The only significant response was an elevation of HR elicited by the highest dose of $\mathrm{MRZ}\left(16 \times 10^{-9}\right.$ $\mathrm{mol}$ ). This tachycardia was reversed by a low dose of naloxone (200 $\mu \mathrm{g} / \mathrm{kg}$, i.v.; Fig. 9A).

Effect of dynorphin microinjections. In additional experiments, Dyn 13 and Dyn 8 were microinjected into artificially ventilated rats (Table I). In the NTS Dyn $13\left(6 \times 10^{-9} \mathrm{~mol}\right)$ significantly reduced MAP without altering $\mathrm{HR}$. A higher dose $\left(60 \times 10^{-9}\right.$ mol $)$ had no consistent effect; neither dose of Dyn 8 altered MAP or HR. NA microinjections of Dyn $13\left(6 \times 10^{-9}\right.$ to $60 \times 10^{-9} \mathrm{~mol}$ ) significantly lowered MAP without changing HR. The responses to Dyn 8 were not significantly different from saline.

\section{Discussion}

Martin and co-workers first postulated the existence of kappa receptors which mediate analgesia but whose agonists, the benzomorphan derivatives, do not exhibit cross-tolerance with morphine (Gilbert and Martin, 1976; Martin et al., 1976). Since these original reports, the function, as well as the distribution, of kappa receptors has been controversial. In recent years, however, kappa or benzomorphan receptors, as well as endogenous ligands for these receptors, have been demonstrated in the periphery and brain of several species, including rat, mouse, guinea pig, and human (Kosterlitz et al., 1981; Wuster et al., 1981; Maurer, 1982; Pfeiffer and Herz, 1982). However, kappa receptors may not be a homogenous receptor population; studies of selective development of tolerance to kappa agonists in vitro have demonstrated different degrees of cross-tolerance among the different agonists (Schulz and Wuster, 1981; Schulz et al., 1981b). Moreover, subclasses of kappa binding have been de-

$5 ; 3 \times 10^{-9} \mathrm{~mol}, 6 ; 16 \times 10^{-9} \mathrm{~mol}, 7 . * *$, Different from saline, $p<0.01$ (Duncan's Multiple Range Test). *, Different from saline, $p<0.05$ (Duncan's Multiple Range Test). $\ddagger$, Different from saline, $p<0.05$ (unpaired, two-tailed Student's $t$ test). 

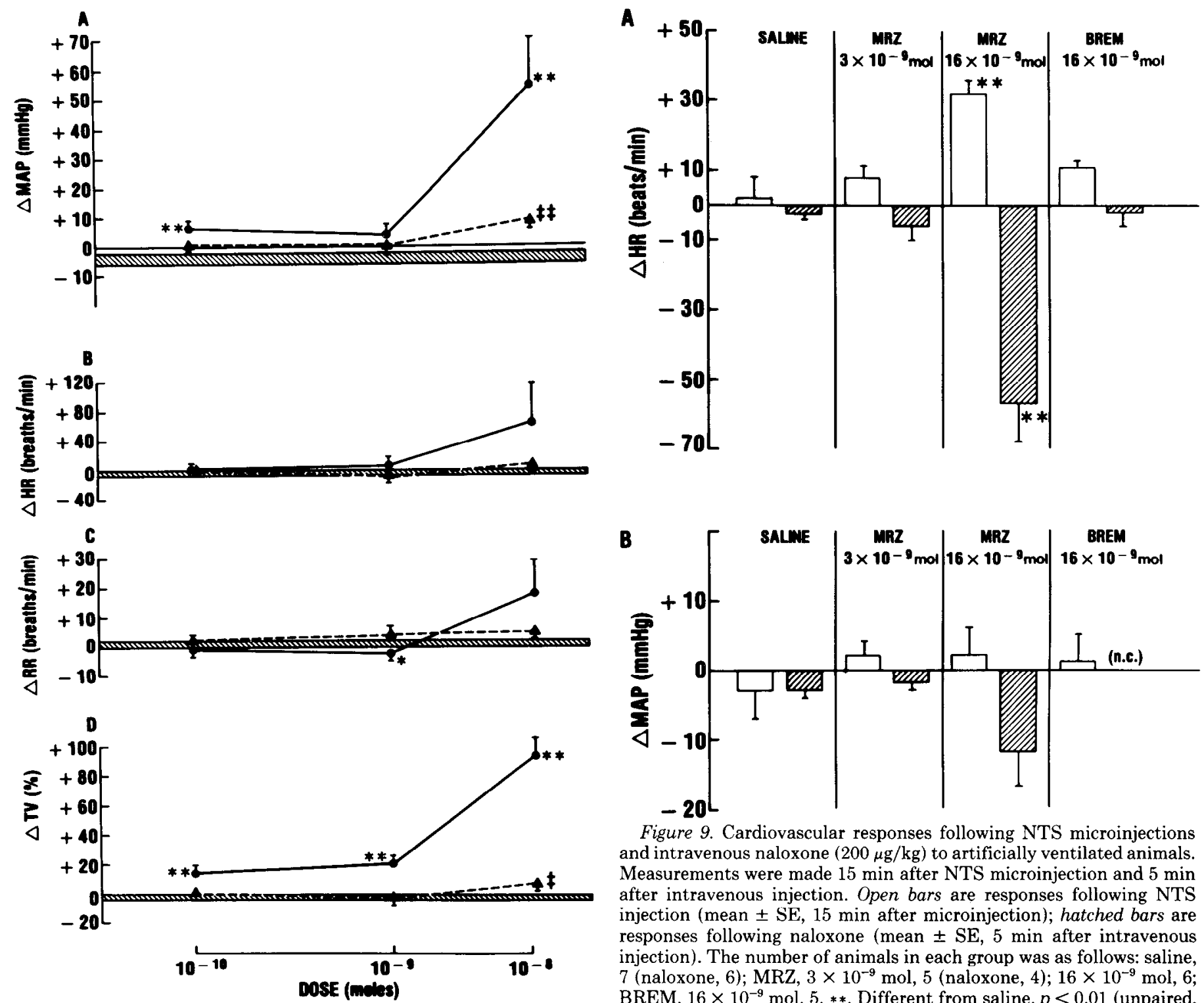

Figure 8. Cardiovascular and respiratory responses to intravenous naloxone $(200 \mu \mathrm{g} / \mathrm{kg})$ following NTS microinjections to spontaneously breathing animals. Measurements were made 5 min after intravenous injection. Solid circles and solid lines refer to MRZ; solid triangles and dashed lines refer to BREM. Hatched areas delineate the mean $\pm \mathrm{SE}$ of saline-treated animals. The number of animals in each group was as follows: saline, 6 ; MRZ, $3 \times 10^{-10} \mathrm{~mol}, 6 ; 3 \times 10^{-9} \mathrm{~mol}, 8 ; 16 \times 10^{-9}$ mol, 4; BREM, $3 \times 10^{-10} \mathrm{~mol}, 5 ; 3 \times 10^{-9} \mathrm{~mol}, 6 ; 16 \times 10^{-9} \mathrm{~mol}, 6 . * *$, Different from saline, $p<0.01$ (Duncan's Multiple Range Test). *, Different from saline, $p<0.05$ (Duncan's Multiple Range Test). $\neq \neq$, Different from saline, $p<0.01$ (unpaired, two-tailed Student's $t$ test). $\ddagger$, Different from saline, $p<0.05$ (unpaired, two-tailed Student's $t$ test).

scribed in human and rat brain (Pfeiffer and Herz, 1982; Pfeiffer et al., 1981).

Dyn 13 and Dyn 8 have been shown to be selectively concentrated within different regions of the brain (Weber et al., 1982). However, study of the actions of these peptides is complicated because Dyn 13 is rapidly metabolized (Herman et al., 1980; Leslie and Goldstein, 1982) and Dyn 8 exhibits enhanced selectivity toward mu receptors (Schulz et al., 1982). Therefore, other compounds exhibiting selectivity toward kappa receptors were also used. BREM and MRZ are benzomorphan derivatives which exhibit kappa-like behavior; they produce analgesia but

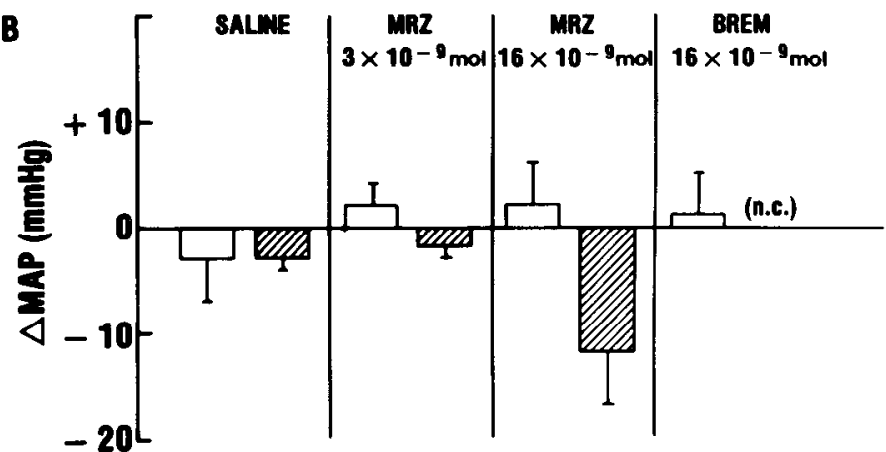

Figure 9. Cardiovascular responses following NTS microinjections and intravenous naloxone $(200 \mu \mathrm{g} / \mathrm{kg})$ to artificially ventilated animals. Measurements were made $15 \mathrm{~min}$ after NTS microinjection and $5 \mathrm{~min}$ after intravenous injection. Open bars are responses following NTS injection (mean $\pm \mathrm{SE}, 15$ min after microinjection); hatched bars are responses following naloxone (mean $\pm \mathrm{SE}, 5 \mathrm{~min}$ after intravenous injection). The number of animals in each group was as follows: saline, 7 (naloxone, 6); MRZ, $3 \times 10^{-9} \mathrm{~mol}, 5$ (naloxone, 4 ); $16 \times 10^{-9} \mathrm{~mol}$, 6; BREM, $16 \times 10^{-9} \mathrm{~mol}, 5 . * *$, Different from saline, $p<0.01$ (unpaired, two-tailed Student's $t$ test).

do not elicit the Straub tail phenomenon (a recognizable tail posture elicited by mu but not kappa agonists) in mice and exhibit limited cross-tolerance with morphine (Merz and Stockhaus, 1979; Romer et al., 1980). BREM does not produce mydriasis in mice, nor has it been reported to affect respiration in rats (Romer et al., 1980). Binding assays in vitro have shown both compounds binding to kappa receptors; however, binding with high affinity to mu and delta receptors was also observed (Pfeiffer et al., 1981; Wood et al., 1981). Since BREM exists as an active $(-)$ as well as inactive $(+)$ stereoisomer (Romer et al., 1980), the enantiomers were used to determine whether responses exhibit stereospecificity. MRZ, which exhibits limited cross-tolerance with other kappa agonists (Schulz and Wuster, 1981; Schulz et al., 1981b), was used to ascertain the presence of kappa isoreceptors.

Using a concentrated fast green solution, the injection sites were shown to be localized to the dorsomedial medulla in the area of the nucleus of tractus solitarius caudal to the obex and to the ventrolateral medulla in the area of the NA rostral to the obex. The pattern of diffusion was similar to that previously described for injertion volumes of less than $0.5 \mu \mathrm{l}$ (Myers, 1966; Zandberg and De Jong, 1977; Matsuguchi et al., 1982). Each 
TABLE I

Effect of dynorphin microinjections

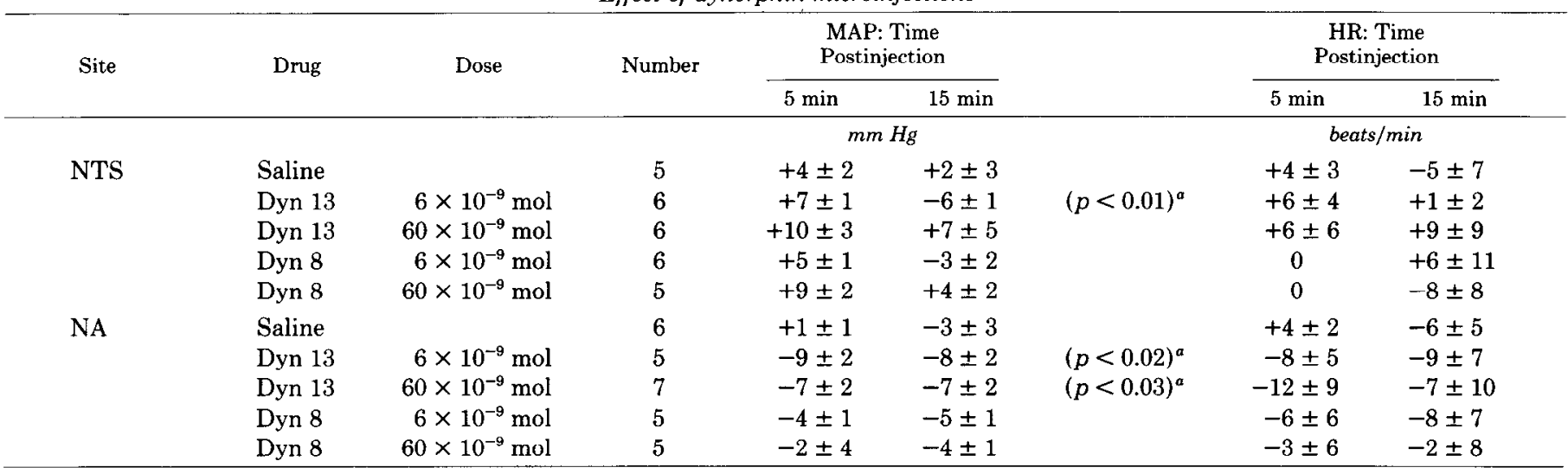

${ }^{a}$ Significant when compared with saline, by ANOVA with repeated measures.

injection site contains neurons commonly ascribed to different nuclei but which are in close proximity to one another. In the dorsomedial site the commissural nucleus of tractus solitarius, the dorsal motor nucleus of the vagus, and the A2 catecholamine group appears to be intermixed (Dennison et al., 1981; Ritchie et al., 1982), whereas the NA, the lateral reticular nucleus, and the A1 catecholamine group are all within or adjacent to the ventrolateral injection area (Armstrong et al., 1982; Rea et al., 1982; Ritchie et al., 1982). These nuclei are important in both cardiovascular and respiratory regulation; in the rat, vagal cardiac preganglionic neurons originate in the NA as well as the dorsal motor nucleus of the vagus (Dennison et al., 1981; Kalia and Sullivan, 1982; Nosaka et al., 1982), baroreceptor afferents terminate in the commissural nucleus of tractus solitarius (Ross et al., 1981; Contreras et al., 1982), and many neurons in both injection sites exhibit respiration-related activity (Cohen, 1979).

In artificially ventilated animals, Dyn 13 but not Dyn 8 significantly lowered MAP following NA microinjection. MRZ and BREM produced dose-related, naloxone-insensitive decreases in MAP. These responses are stereospecific as the (+)enantiomer of BREM had no effect. In the NTS only the low dose of Dyn 13 altered MAP. Neither MRZ, BREM, nor the dynorphins consistently altered HR. In the NA bradycardia was elicited by the highest dose of BREM, whereas in the NTS the only response was tachycardia elicited by the highest dose of MRZ. Moreover, in contrast to naloxone's lack of antagonistic activity against the depressor and bradycardic effects of MRZ and BREM, the tachycardia elicited in the NTS by MRZ was reversed by naloxone. Some kappa responses are reversed by low doses of naloxone (Metcalf et al., 1979; Wood and Rackham, 1981); however, higher doses of this mu-selective antagonist are usually required (Hutchinson et al., 1975; Pickworth and Sharpe, 1979). Thus, our observation that doses of naloxone up to 10 times that needed to reverse the cardiovascular actions of mu agonists did not alter the decrease in MAP elicited by the kappa agonists suggests that these responses are mediated by a non-mu receptor, presumably the kappa receptor. The naloxone-sensitive tachycardia elicited by MRZ at high doses in the N'TS might have resulted from an interaction of this compound with mu receptors.

Since MAP and HR were decreased by the benzomorphan compounds following NTS injections in spontaneously breathing but not artificially ventilated animals, these cardiovascular responses are probably secondary to respiratory depression. Similar responses were observed by Bellet et al. (1980) following intracisternal administration of opioids in anesthetized rats. In our laboratory, after injection of $\mathrm{mu}$ agonists into the NA
(Hassen et al., 1983), respiratory depression was observed, accompanied by a decrease in MAP and HR, masking the pressor responses and tachycardia elicited by $\mathrm{mu}$ agonists in artificially respired animals. Such changes, which are associated with hypoxia, hypercapnia, and acidosis (Bellet et al., 1980; Hassen et al., 1983), may result from direct alteration of cardiac or vascular activity or from a modification of cardiovascular responses by chemoreceptor reflexes. Decreased thoracic movements associated with respiration may also contribute to an alteration of cardiac output. These observations serve to emphasize the importance of using artificially ventilated animals when studying the cardiovascular responses to opioids because such responses may be substantially changed by the concomitant respiratory effects of these drugs.

The cardiovascular and respiratory responses elicited by MRZ following NTS and NA microinjections differ from those seen following intracerebroventricular injections in awake, freely moving rats (Pfeiffer et al., 1983b). Although no respiratory responses were observed in the latter preparation, MRZ elicited an increase in MAP and HR. The pressor response was not altered by pretreatment with the long-lasting mu antagonist $\beta$-funaltrexamine but was antagonized by the kappa antagonist MR 2266. The increase in HR was attenuated by both antagonists. The different responses elicited from anesthetized and awake animals may be due, in part, to the presence of anesthesia, since pentobarbital may alter autonomic activity (Murthy et al., 1982; Zumpfer et al., 1982). Alternatively, as shown previously (Faden and Feuerstein, 1983) and in the present study, opioid responses are site-specific. Thus, the responses following intracerebroventricular injections may be due to a summation of cardiovascular effects elicited from multiple sites.

In addition to the cardiovascular effect, MRZ was a potent respiratory depressant, and BREM also elicited small decreases in respiration. Unlike mu agonists, which decreased TV when injected into the NTS but not the NA (Hassen et al., 1982, 1983), injections of MRZ into both nuclei elicited dose-related decreases in TV. In addition, MRZ and mu agonists had qualitatively different effects on respiratory rate. MRZ, except for a decrease in rate following high doses injected into the NTS, was without effect, whereas the highly selective mu agonist D$\mathrm{Ala}^{2}, \mathrm{MePhe}^{4}, \mathrm{Gly}_{-} \mathrm{l}^{5}$ enkephalin (DAGO) and the relative delta-mu antagonist D-Ala ${ }^{2}, \mathrm{D}-\mathrm{Leu}^{5}$ enkephalin (DADL) elicited dose-related changes in respiratory rate from both NTS and NA. In contrast to the lack of a naloxone antagonism of the cardiovascular depressor responses, the respiratory effects of MRZ were reversed by low doses of naloxone. Although the sensitivity to naloxone appears to suggest that the respiratory actions of MRZ result from interactions with mu receptors in 
these nuclei, the difference between these responses and those of mu agonists may indicate the presence of either subtypes of mu receptors or yet another naloxone-sensitive receptor. Alternatively, since BREM elicited only small respiratory responses, MRZ may modify respiration via a naloxone-sensitive subtype of kappa receptor.

The cardiovascular responses to the benzomorphans and Dyn 13 are distinctly different from those elicited by relative mu agonists microinjected into the same nuclei (Hassen et al. 1982, 1983). DAGO and DADL both elicited dose-related, naloxone-sensitive increases in MAP and HR from both the NTS and NA. However, DAGO was consistently more potent than DADL. Although comparison of the cardiovascular actions of endogenous opioids in the NA has not been done, in the NTS methionine- and leucine-enkephalin, which activate both $\mathrm{mu}$ and delta receptors (Kosterlitz and Paterson, 1980), elicit increased blood pressure and HR (Petty and De Jong, 1983); $\beta$ endorphin, which is selective toward epsilon but not kappa receptors (Oka et al., 1980; Kosterlitz et al., 1981; Wood et al., 1981), decreases pressure and rate (Petty and De Jong, 1982). Taken together, these data suggest that multiple opioid receptors have different, site-specific roles in hemodynamic and cardioregulatory functions in the hindbrain.

\section{References}

Armstrong, D. M., C. A. Ross, V. M. Pickel, T. H. Joh, and D. J. Reis (1982) Distribution of dopamine-, noradrenaline-, and adrenalinecontaining cell bodies in the rat medulla oblongata: Demonstrated by immunocytochemical localization of catecholamine biosynthetic enzymes. J. Comp. Neurol. 212: 173-187.

Bellet, M., J. L. Elghozi, P. Meyer, M. G. Pernollet, and H. Schmitt (1980) Central cardiovascular effects of narcotic analgesics and enkephalins in rats. Br. J. Pharmacol. 71: 365-369.

Bolme, P., K. F. Fuxe, L. F. Agnati, R. Bradley, and J. Smythies (1978) Cardiovascular effects of morphine and opioid peptides following intracisternal administration in chloralose-anesthetized rats. Eur. J. Pharmacol. 48: 319-324.

Chang, K. -J., B. R. Cooper, E. Hazum, and P. Cuatrecasas (1979) Multiple opiate receptors: Differential regional distribution in the brain and differential binding of opiates and opioid peptides. Mol. Pharmacol. 16: 91-104.

Chavkin, C., I. F. James, and A. Goldstein (1982) Dynorphin is a specific endogenous ligand of the kappa opioid receptor. Science 215: $413-415$.

Cohen, M. I. (1979) Neurogenesis of respiratory rhythm in the mammal. Physiol. Rev. 59: 1105-1172.

Contreras, R. J., R. M. Beckstead, and R. Norgren (1982) The central projections of the trigeminal, facial, glossopharyngeal and vagus nerves: An autoradiographic study in the rat. J. Autonom. Nerv. Syst. 6: 303-322.

Della Bella, D., F. Casacci, and A. Sassi (1978) Opiate receptors: Different ligand affinity in various brain regions. Adv. Biochem. Psychopharmacol. 18: 271-277.

Dennison, S. J., V. E. Merritt, M. H. Aprison, and D. L. Felten (1981) Redefinition of the location of the dorsal (motor) nucleus of the vagus in the rat. Brain Res. Bull. 6: 77-81.

Faden, A. 1. and G. Z. Feuerstein (1983) Hypothalamic regulation of the cardiovascular and respiratory systems: Role of specific opiate receptors. Br. J. Pharmacol. 79: 997-1002.

Feuerstein, G., and A. I. Faden (1982) Differential cardiovascular effects of $\mu, \delta$ and $\kappa$ opiate agonists at discrete hypothalamic sites in the anesthetized rat. Life Sci. 31: 2197-2200.

Feuerstein, G., C. J. Molineaux, J. G. Rosenberger, A. I. Faden, and B. M. Cox (1983) Dynorphins and Leu-enkephalin in brain nuclei and pituitary of WKY and SHR rats. Peptides 4: 225-229.

Florez, J., L. E. McCarthy, and H. L. Borison (1968) A comparative study in the cat of the respiratory effects of morphine injected intravenously and into the cerebrospinal fluid. J. Pharmacol. Exp. Ther. 163: 448-455.

Gilbert, P. E., and W. R. Martin (1976) The effects of morphine and nalorphine-like drugs in the nondependent, morphine-dependent and cyclazocine-dependent chronic spinal dog. J. Pharmacol. Exp. Ther. 198: 66-82.
Hassen, A. H., G. Feuerstein, and A. I. Faden (1982) $\mu$ receptors and opioid cardiovascular effects in the NTS of rat. Peptides 3: 10311037.

Hassen, A. H., G. Feuerstein, and A. I. Faden (1983) Selective cardiovascular effects mediated by mu opioid receptors in the nucleus ambiguus. Neuropharmacology 23: 407-415.

Herman, B. H., F. Leslie, and A. Goldstein (1980) Behavioral effects and in vivo degradation of intraventricularly administered dynorphin-(1-13) and D-Ala ${ }^{2}$-dynorphin-(1-11) in rats. Life Sci. 27: 882892.

Hutchinson, M., H. W. Kosterlitz, F. M. Leslie, A. A. Waterfield, and L. Terenius (1975) Assessment in the guinea pig ileum and mouse vas deferens of benzomorphans which have strong antinociceptive activity but do not substitute for morphine in the dependent monkey. Br. J. Pharmacol. 55: 541-546.

Kalia, M., and J. M. Sullivan (1982) Brainstem projection of sensory and motor components of the vagus nerve in the rat. J. Comp. Neurol. 211: 248-264.

Khachaturian, H., S. J. Watson, M. E. Lewis, D. Coy, A. Goldstein, and H. Akil (1982) Dynorphin immunocytochemistry in the rat central nervous system. Peptides 3: 941-945.

Kosterlitz, H. W., and S. J. Paterson (1980) Characterization of opioid receptors in nervous tissue. Proc. R. Soc. Lond. (Biol). 210: 113-122.

Kosterlitz, H. W., S. J. Paterson, and L. E. Robson (1981) Characterization of the $\kappa$-subtype of the opiate receptor in the guinea pig brain. Br. J. Pharmacol. 73: 939-949.

Laubie, M., H. Schmitt, M. Vincent, and G. Remond (1977) Central cardiovascular effects of morphinomimetic peptides in dogs. Eur. J. Pharmacol. 46: 67-71.

Leslie, F. M., and A. Goldstein (1982) Degradation of dynorphin-(113 ) by membrane-bound rat brain enzymes. Neuropeptides $2: 185-$ 196.

Leslie, F. M., C. Chavkin, and B. M. Cox (1980) Opioid binding properties of brain and peripheral tissues: Evidence for heterogeneity in opioid ligand binding sites. J. Pharmacol. Exp. Ther. 214: 395402.

Lord, J. A. H., A. A. Waterfield, J. Hughes, and H. W. Kosterlitz (1977) Endogenous opioid peptides: Multiple antagonists and receptors. Nature 267: 495-499.

Martin, W. R., C. G. Eades, J. A. Thompson, R. E. Huppler, and P. E. Gilbert (1976) The effects of morphine- and nalorphine-like drugs in the nondependent and morphine-dependent chronic spinal dog. J. Pharmacol. Exp. Ther. 197: 517-532.

Matsuguchi, H. F., M. Sharabi, F. J. Gordon, A. K. Johnson, and P. G. Schmid (1982) Blood pressure and heart rate responses to microinjection of vasopressin into the nucleus tractus solitarius region of the rat. Neuropharmacology 21: 687-693.

Maurer, R. (1982) Multiplicity of opiate receptors in different species. Neurosci. Lett. 30: 303-307.

Merz, H., and K. Stockhaus (1979) $N$-\{(Tetrahydrofury)alkyl $\}$ and $N$ (alkoxyalkyl) derivatives of $(-)$-normetazocine, compounds with differentiated opioid action properties. J. Med. Chem. 22: 1475-1483.

Metcalf, G., J. M. H. Rees, and S. J. Ward (1979) In vivo antagonism of analgesia and respiratory depression induced by proposed $\mu$ and $\delta$ opiate antagonists. Br. J. Pharmacol. 66: 473P-474P.

Molineaux, C. J., G. Feuerstein, A. I. Faden, and B. M. Cox (1982) Distribution of immunoreactive dynorphin in discrete brain nuclei; comparison with vasopressin. Neurossi. I ett. 33: 179-184.

Murthy, V. S., M. E. Zagan, R. R. Vollmer, and D. H. Schmidt (1982) Pentobarbital-induced changes in vagal tone and reflex vagal activity in rabbits. Eur. J. Pharmacol. 84: 41-50.

Myers, R. D. (1966) Injection of solutions into cerebral tissue: Relation between volume and diffusion. Physiol. Behav. 1: 171-174.

Nosaka, S., K. Yasunaga, and S. Tamai (1982) Vagal cardiac preganglionic neurons: Distribution, cell types and reflex discharges. Am. J. Physiol 243: R92-R98.

Oka, 'I', K. Negishi, M. Suda, 'I. Matsumuja, 'I'. Inazu, and M. Ueki (1980) Rabbit vas deferens: A specific bioassay for opioid $k$-receptor agonist. Eur. J. Pharmacol. 73: 235-236.

Oka, T., K. Negishi, M. Suda, A. Sawa, M. Fujino, and M. Wakimasu (1982) Evidence that dynorphin-(1-13) acts as an agonist on opioid к-receptors. Eur. J. Pharmacol. 77: 137-141.

Paxinos, G., and C. Watson (1982) The Rat Brain in Stereotaxic Coordinates, Academic Press, Inc., New York

Petty, M. A., and W. De Jong (1982) Cardiovascular effects of $\beta$ endorphin after microinjection into the nucleus tractus solitarii of the anesthetized rat. Eur. J. Pharmacol. 81: 446-457. 
Petty, M. A., and W. De Jong (1983) Enkephalins induce a centrally medialed rise in blood pressure in rats. Brain. Res. 260: 322-325.

Pfeiffer, A., and A. Herz (1982) Discrimination of three opiate-receptor binding sites with the use of a computerized curve fitting technique. Mol. Pharmacol. 21: 266-271.

Pfeiffer, A., A. Pasi, P. Mehraein, and A. Herz (1981) A subclassification of $\kappa$-opiate receptor sites in human brain by use of dynorphin 117. Neuropeptides 2: 89-97.

Pfeiffer, A., G. Feuerstein, I. J. Kopin, and A. I. Faden (1983a) Cardiovascular and respiratory effects of $\mu-, \delta$ - and $\kappa$-opiate antagonists microinjected into the anterior hypothalamic brain area of awake rats. J. Pharmacol. Exp. Ther. 225: 735-741.

Pfeiffer, A., G. Feuerstein, R. L. Zerbe, A. I. Faden, and I. J. Kopin (1983b) Mu receptors mediate opioid cardiovascular effects at anterior hypothalamic sites through sympatho-adrenomedullary and parasympathetic pathways. Endocrinology 113: 929-938.

Pickworth, W. B., and L. G. Sharpe (1979) EEG-behavioral dissociation after morphine- and cyclazocine-like drugs in the dog: Further evidence for two opiate receptors. Neuropharmacology 18: 617-622.

Rea, M. A., M. H. Aprison, and D. L. Felten (1982) Catecholamines and serotonin in the caudal medulla of the rat: Combined neurochemical-histofluorescence study. Brain Res. Bull 9: 227-236.

Ritchie, T. C., K. N. Westlund, R. M. Bowker, J. D. Coulter, and R. B. Leonard (1982) The relationship of the medullary catecholamine containing neurons to the vagal motor nuclei. Neuroscience $7: 1471-$ 1482.

Romer, D., H. Buscher, R. C. Hill, R. Maurer, T. J. Petcher, H. B. Welle, H. C. Bakel, and A. M. Akkerman (1980) Bremazocine: A potent long-acting opiate kappa agonist. Life Sci. 27: 971-978.

Ross, C. A., D. A. Ruggiero, and D. J. Reis (1981) Afferent projections to cardiovascular portions of the tractus solitarius in the rat. Brain
Res. 223: 402-408.

Schulz, R., and M. Wuster (1981) Are there subtypes (isoreceptors) of multiple opiate receptors in the mouse vas deferens? Eur. J. Pharmacol. 76: 61-66.

Schulz, R., M. Wuster, and A. Herz (1981a) Pharmacological characterization of the $\epsilon$ opiate receptor. J. Pharmacol. Exp. Ther. 216 . 604-606.

Schulz, R., M. Wuster, P. Rubini, and A. Herz (1981b) Functional opiate receptors in the guinea pig ileum: Their differentiation by means of selective tolerance development. J. Pharmacol. Exp. Ther. 219: $547-550$.

Schulz, R., M. Wuster, and A. Herz (1982) Endogenous ligands for $\kappa$ opiate receptors. Peptides 3: 973-976.

Weber, E., C. J. Evans, and J. D. Barchas (1982) Predominance of the aminoterminal octapeptide fragment of dynorphin in rat brain regions. Nature 299: 77-79.

Wood, P. L., and A. Rackham (1981) Actions of kappa, sigma and partial mu narcotic receptor agonists on rat brain acetylcholine turnover. Neurosci. Lett. 23: 75-80.

Wood, P. L., S. E. Charleson, D. Lane, and R. L. Hudgin (1981) Multiple opiate receptors: Differential binding of $\mu, \kappa$ and $\delta$ agonists. Neuropharmacology 20: 1215-1220.

Wuster, M., R. Schulz, and A. Herz (1981) Multiple opiate receptors in peripheral tissue preparations. Biochem. Pharmacol. 30: 18831887.

Zandberg, P., and W. De Jong (1977) Localization of catecholaminergic receptor sites in the nucleus tractus solitarius involved in the regulation of arterial blood pressure. Prog. Brain Res. 47: 117-122.

Zumpfer, M., W. T. Manders, A. C. Barger, and S F. Vatner (1982) Pentobarbital alters compensatory neural and humoral mechanisms in response to hemorrhage. Am. J. Physiol. 243: H713-H721. 